\title{
Adaptation of intelligent control systems to technological processes of oil-and-gas production enterprises
}

\author{
lakov Korovin ${ }^{1, a}$ \\ ${ }^{1}$ Southern Federal University, Rostov-on-Don, Russia
}

\begin{abstract}
The paper is dedicated to research, supported by the Russian Scientific Foundation that is targeted on the development of novel technology of oil enhancement recovery, based on the hybrid application of various artificial intelligence techniques. An approach of dynamic control of electric submersible oil pump is suggested. The key idea is a real time technological management, applying artificial neural network tool. Research evaluation results are presented.
\end{abstract}

\section{Adaptation of Intelligent Control Systems To Technological Processes Of Oil-And-Gas Production Enterprises}

At present reduction of production cost of hydrocarbon feed by means of complex intellectualization of control processes of technological objects for oil-and-gas production industry is a pressing scientific problem. In modern conditions, when the majority of oilfields are hard-to-extract ones, when costs of products are relatively low, and competition between world oil-and-gas production companies is relentless, optimization of technological processes of oil-and-gas production become a key problem. The most promising approach to solution of the specified problem is adaptation of facilities for generation of actual and effective recommendations on accepted control decisions concerning functional and strategic horizons of scheduling. It can be achieved by means of implementation of modern, complex approaches to data processing which cover all stages of hydrocarbon feed production [1].

Problems of development and adaptation of control of oil production enterprises had been actively solved since the middle of the 50-s. However, these problems were solved slowly and without any sufficient effect because of a number of reasons. The main reasons which restrained development of control were the following. Not all processes and objects were controlled. Automation implemented not a complex, which is why not relieve the operational staff, management structure of the enterprise was not perfect, economic effectiveness was not provided. Control facilities were adjusted to existing equipment, outdated, unreliable, and unsuitable for control in some cases. Control facilities and controlled equipment were not a single whole. Vendors produced equipment and control facilities separately. Equipment which was used for oil production was installed without obligatory control tools. Facilities and systems of control and remote control were designed for large number of flowcharts of field gathering and oil-andgas treatment. In some cases these flowcharts were not optimal for control. As a result, a large number of types and designs of control and remote control was created, and it complicated organization of serial production and increased costs, though quality of such devices was low.

At present Russian specialists and scientific teams carry out ambitious works, concerning creation of control systems for oilfield production, but they do not take into account transition of quantitative modifications of parameters into qualitatively new condition of the system. Such transition is not always evident for traditional mathematical formalization of the process [2].

Owing to adaptation of an adequate model of an oil production complex, it will be possible to organize timely preventive actions for reduction of idle-time of equipment. At the same time, analysis of data of technological processes will provide the personnel of the oil-and-gas enterprise with tools of effective scheduling of the used methods of reservoir stimulation for long-time increasing indices of reservoir recovery rate. At present, these problems are the most needed for organization of control of oil production processes during the whole life of the oilfield.

It is possible to achieve a higher level of control of technological objects, including approaches to analysis and prediction of equipment failures, time per fault on workshop (manufactory) tier by means of implementation of modern methods of deep data analysis with use of neural networks [3].

Owing to use of intelligent approaches to estimation of real-time changes and logs, it is possible to form in an automatic mode (if it is necessary) regulatory and control actions for technological equipment of control objects of pump stations, providing constant control of operability

\footnotetext{
${ }^{a}$ Corresponding author: korovin_yakov@mail.ru
} 
of the main and auxiliary equipment of technological control objects of pump stations.

Adaptation of these facilities will provide not only safe functioning of the main and auxiliary equipment of control objects of a pump station in all operation conditions, but also anticipatory actions to increase effectiveness of functioning of controlled equipment. Automatic diagnostics of condition and adaptive control of technical facilities also contribute to reduction of the number of stoppage and failures of technological equipment. As a result, idle time of equipment drops down and its loading become optimal.

In general, the main tendencies of development of automatic control systems are as follows:

- Growth of the performance of automatic control systems;

- Increasing of the number of interfaces for connection with external oil-well data sources (various sensors);

- Capability of storing and processing of large data arrays;

- Increasing of quantity and complexity of control algorithms.

Further development of the tendencies, described above, will unavoidably lead to development of a complex of so-called "digital well". Evidently, a highperformance reliable controller CS ESP will play the main role in this complex.

To provide more effective adaptation of intelligent control systems, we have decided to use frequency converters (FC) [4]. At the moment they are the only devices which provide regulation of rotary speed of an asynchronous motor.

Use of frequency converters has a number of main advantages, such as:

- Smooth start of both the motor and the pump equipment. At the start moment the spinup of the pump impeller is gradual and smooth until the set-up operating parameters are achieved. Just owing to this fact it is possible to achieve a considerable reduction of mechanical loads to the pump, and also reduce starter current. As a result, risk of hydraulic impacts is also considerably reduced.

- Besides, owing to this, the resource of the pump equipment is consumed more efficiently, and hence, its life of operation grows. Also, we should pay attention to the well, which can experience hydraulic impacts;

- If water supply is performed by a well pump without use of a special, accumulator bottle (hydraulic accumulator) of diafragm (i.e. directly), and the water draw-off does not exceed the pump delivery, then use of frequency converter in this case will regulate both the pump power and the water draw-off owing to reduction of the rotation rate of the pump impeller. In turn, the less the power, the better saving of electric energy.

So, use of frequency converters provides more effective adaptation owing to smooth control of pump equipment.

Summing up everything that was said above, we can conclude, that the worldwide tendency of "intellectualization" of oil production control systems is to transfer more and more number of functions directly to the controlled mechanism, and is the necessary condition which provides a considerable growth of production rate, and above all to increase the equipment life.

\section{The Experimental Results And Benefits}

For the analysis of offered method of sharing of a set of neural networks efficiency, the following experiment was conducted [5][6][7][8][9][10][11][12][13][14]. Nine test samples, with quantity of various classes from 1 to 256 were prepared. Further each test sample was classified with use application from 1 to 256 neural networks, in each case the quantity of neural networks didn't exceed the quantity of classes in the sample. In tab. 1 the bottom triangular matrix, describing the results of classification of each test sample (lines) at various number of neural networks (columns) is represented.

Table 1. The table of dependence of classification quality on various test sample classes and neural networks number.

\begin{tabular}{|c|c|c|c|c|c|c|c|c|c|}
\hline classes & $\mathbf{1}$ & $\mathbf{2}$ & $\mathbf{4}$ & $\mathbf{8}$ & $\mathbf{1 6}$ & $\mathbf{3 2}$ & $\mathbf{6 4}$ & $\mathbf{1 2 8}$ & $\mathbf{2 5 6}$ \\
\hline 1 & 0.99 & $\mathrm{X}$ & $\mathrm{X}$ & $\mathrm{X}$ & $\mathrm{X}$ & $\mathrm{X}$ & $\mathrm{X}$ & $\mathrm{X}$ & $\mathrm{X}$ \\
\hline 2 & 0.96 & 0.97 & $\mathrm{X}$ & $\mathrm{X}$ & $\mathrm{X}$ & $\mathrm{X}$ & $\mathrm{X}$ & $\mathrm{X}$ & $\mathrm{X}$ \\
\hline 4 & 0.86 & 0.89 & 0.92 & $\mathrm{X}$ & $\mathrm{X}$ & $\mathrm{X}$ & $\mathrm{X}$ & $\mathrm{X}$ & $\mathrm{X}$ \\
\hline 8 & 0.81 & 0.82 & 0.87 & 0.91 & $\mathrm{X}$ & $\mathrm{X}$ & $\mathrm{X}$ & $\mathrm{X}$ & $\mathrm{X}$ \\
\hline 16 & 0.78 & 0.81 & 0.83 & 0.85 & 0.9 & $\mathrm{X}$ & $\mathrm{X}$ & $\mathrm{X}$ & $\mathrm{X}$ \\
\hline 32 & 0.72 & 0.76 & 0.79 & 0.82 & 0.86 & 0.89 & $\mathrm{X}$ & $\mathrm{X}$ & $\mathrm{X}$ \\
\hline 64 & 0.66 & 0.71 & 0.74 & 0.8 & 0.82 & 0.85 & 0.87 & $\mathrm{X}$ & $\mathrm{X}$ \\
\hline 128 & 0.6 & 0.65 & 0.69 & 0.74 & 0.75 & 0.79 & 0.82 & 0.84 & $\mathrm{X}$ \\
\hline 256 & 0.59 & 0.61 & 0.67 & 0.7 & 0.71 & 0.73 & 0.76 & 0.8 & 0.82 \\
\hline
\end{tabular}

From the table it can be seen that the best quality of classification is reached when the number of neural networks is equal to the maximum number of possible classes. The graph of classification quality dependence of initial test set, handled by one neural network (dotted line) is shown at Fig.1 so as the graph of recognition quality dependence of initial test set, handled by a set of the neural networks corresponding to each set classes quantity (continuous line).

Thus, the hypothesis of efficiency of application of "its private" neural network for each class handling [7] is experimentally proved.

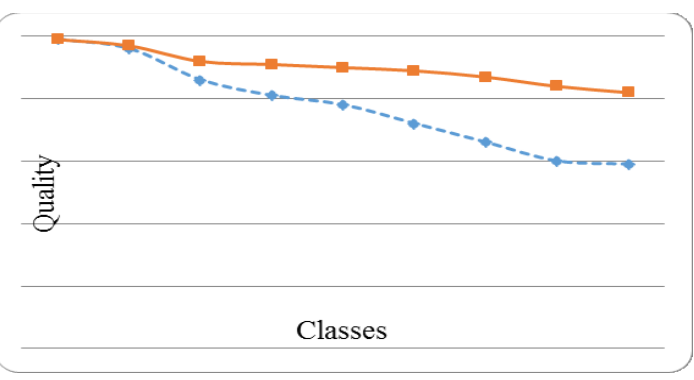

Figure 1. Classification quality dependence of initial test set, handled by one neural network and by a set of the neural networks. 


\section{Acknowledgement}

This paper is published due the financial support of the Russian Science Foundation (RSF) via the grant No 15-19- 00196.

\section{References}

1. A.D. Brents, Automatic control systems in oil-andgas industry. - Moscow: Nedra, (1982). 27 p.

2. Y.A. Balakirov, L.V. Kapushchak, E.A. Slepyan, Optimal control of oil production processes. -Kiyev: TECHNICS, (1987). 119 p.

3. S.A. Alyokhin, S.G. Kipnis, V.A. Orudzhev, A.K. Ostrovskaya, Automatization of intermittent functioning well. - M.:Nedra. (1980). 32 p.

4. Frequency converters for a well pump [On-line resource]. Access: http://moikolodets.ru/chastotnyjpreobrazovatel-dlya-skvazhinnogo-nasosa-518

5. S.V. Kononov, S.Ya. Korovin, Neftyanoe khozyaystvo - Oil Industry, 2006, no. 10, pp 10 -14

6. G.A. Galuev, Ya.S. Korovin, S.Ya. Korovin, S.N. Matveev, Radiotechnika, (2006), no. 3, pp. 42-49.

7. Ya.S. Korovin, Neftyanoe khozyaystvo - Oil Industry, (2007), no. 1, pp 80- 85.

8. D.P. Wasserman, Neural computing: theory and practice, Van Nostrand Reinhold, (1989), $220 \mathrm{p}$.

9. W.A.S. Clearning, H.G. Zimmermann, R. Neuneier, Neural networks in financial engineering. Proceedings of the Third International Conference on Neural Networks, (1996).

10. Neural networks. STATISTICA Neural Networks, Moscow: Goryachaya liniya-Telecom Publ., (2000), $182 \mathrm{p}$.

11. R. Feraud, F. Clerot, J.L. Simon, D. Pallou, C. Labbe, S. Martin, Kalman and neural network approaches for the control of a vp bandwidth in an atm network. Lecture Notes in Computer Science. Springer-Verlag Gmb. (2000). Vol. 1815, p. 0655.

12. Ju.A. Perez-Ortiz, Ju. Schmidhuber, F.A. Gers, D. Eck, Improving long-term online prediction with decoupled extended kalman filters. Lecture Notes in Computer Science. Springer-Verlag Gmb. (2002). Vol. 2415, p. 1055.

13. Ju.R. Rabunal, Ju. Dorado, A. Pazos, D. Rivero, Rules and generalization capacity extraction from ann with $g p$, Lecture Notes in Computer Science, Springer-Verlag Gmb, (2003). Vol. 2686, pp. 606-613.

14. E. Cantu-Paz, Pruning neural networks with distribution estimation algorithms, Lecture Notes in Computer Science, Springer-Verlag Gmb, (2003). Vol. 2723, pp.790-800.

15. I.S. Korovin, M.V. Khisamutdinov, A.I. Kaliaev, The Application of Evolutionary Algorithms in the Artificial Neural Network Training Process for the Oilfield Equipment Malfunctions' Forecasting, 2nd International Symposium on Computer, Communication, Control and Automation (3CA 2013), Proccedings, pp. 253-257. 